\title{
O CENTRO DE REFERÊNCIA E APOIO À VITIMA(CRAVI) E O TRABALHO COM AS VÍTIMAS DE VIOLÊNCIA INDIRETA
}

\begin{abstract}
Hélio Batista Barboza ${ }^{1}$
RESUMO: Este artigo apresenta e discute o trabalho realizado pelo Centro de Referência e Apoio a vítima (CRAVI). O Centro foi criado em 1988 pela Secretaria da Justiça e Defesa da Cidadania do Estado de São Paulo para apoiar as vítimas indiretas de violência. Os dados aqui apresentados foram obtidos através da observação participante e de entrevistas realizadas com os profissionais que atuam no centro e os usuários. Buscou-se identificar os aspectos centrais desta experiência, tanto do ponto de vista da gestão como da atuação direta com os usuários e da resolutividade das ações empreendidas.
\end{abstract}

PALAVRAS CHAVE: Violência Indireta, Violência Urbana, Cidadania, Centro de Referência, Apoio.

ABSTRACT: This article presents and discusses the work done by the Center for Reference and support the indirect victim of violence. The Center was established in 1988 by the Department of Justice and Defense of Citizenship of the Sao Paulo State to support the indirect victims of violence. The data presented here was obtained through participant observation and interviews with professionals who work in the center and with the users. We tried to identify the core aspects of this experience, both in terms of management and the resoluteness of the actions undertaken.

KEYWORDS: Indirect Violence, Urban Violence, Citizenship, Center of Reference, Support

${ }^{1}$ Mestre em Administração Pública . Helio.barboza@gmail.com 


\section{Introdução}

A gravidade da violência nas grandes cidades brasileiras é bastante conhecida e não faltam estatísticas para comprová-la. Em 2002, o total de vítimas de homicídio na Região Metropolitana de São Paulo chegou ao assombroso número de 10.682 pessoas. $^{2}$ No município de São Paulo, a polícia registrou 4.260 homicídios e 138 latrocínios em 2004, com uma média de 12 ocorrências por dia. ${ }^{3}$

Menos conhecido é o drama das chamadas "vítimas indiretas”, que são os familiares de quem perde a vida nas ciladas da violência urbana. Para estes, cada assassinato tem como conseqüência traumas psicológicos, perdas financeiras e questões sociais de difícil superação. Visto por esse ângulo, o problema da violência ganha dimensões ainda mais graves, afetando famílias e até comunidades inteiras. Embora a violência atinja todas as classes sociais, estão entre as pessoas de baixa renda e nos bairros da periferia o maior número de viúvos e órfãos, que nem sempre possuem informações suficientes a respeito de seus direitos. Além disso, o trauma causado pela morte repentina de um parente muitas vezes imobiliza as pessoas e impede que elas reconstruam suas vidas. Também é comum que, movidas por um sentimento de vingança e pela descrença em relação às instituições públicas (polícia, poder Judiciário, etc.), elas procurem fazer justiça com as próprias mãos e realimentem o ciclo da violência.

Para apoiar as vítimas indiretas da violência urbana, a Secretaria da Justiça e Defesa da Cidadania do Estado de São Paulo criou em 1998 o Centro de Referência e Apoio à Vítima (Cravi), em parceria com a Secretaria de Assistência e Desenvolvimento Social, a Procuradoria Geral do Estado e a Secretaria de Estado de Direitos Humanos, ligada ao Ministério da Justiça. A implementação do serviço também contou com a colaboração da Faculdade de Serviço Social da Pontifícia Universidade Católica de São Paulo (PUC-SP) e da organização não-governamental Instituto Sou da Paz.O Cravi, também tem parcerias com o Instituto Therapon Adolescência (uma ONG especializada no atendimento psicológico a adolescentes), e o Instituto São Paulo contra a Violência (ONG que tem por objetivo apoiar políticas de redução da criminalidade).

\footnotetext{
${ }^{2}$ Fonte: Ministério da Justiça / Secretaria Nacional de Segurança Pública (Senasp); Ministério da Saúde / Fundação Nacional de Saúde (Funasa). http://www.mj.gov.br/senasp/pesquisas aplicadas/saude/regiões

${ }^{3}$ Fonte: Secretaria de Segurança Pública do Estado de São Paulo. http://www.ssp.sp.gov.br/estatisticas/_porregiao.aspx?codigo=1
} 
A gestão do Centro é compartilhada com esses parceiros, que também fornecem parte dos técnicos da instituição.

\section{Objetivos}

O Cravi oferece atendimento integrado nas áreas social, jurídica e psicológica aos familiares das vítimas de assassinato e às vítimas de tentativa de homicídio. Além dos atendimentos prestados na própria sede, o Centro encaminha seus usuários, sempre que necessário, para outros órgãos públicos ou organizações não-governamentais.

A implantação do Cravi atende a disposições da Constituição de 1988, mais especificamente os artigos 245 e 278:

Art. 245 - A Lei disporá sobre as hipóteses e condições em que o Poder Público dará assistência aos herdeiros e dependentes carentes de pessoas vitimadas por crime doloso, sem prejuízo da responsabilidade civil do autor do ilícito.

Art. 278 - O Poder Público promoverá programas especiais, admitindo a participação de entidades não governamentais e tendo como propósito:

(...)

VI - instalação e manutenção de núcleos de atendimento especial e casas destinadas ao acolhimento provisório de crianças, adolescentes, idosos, portadores de deficiências e vítimas de violência, incluindo a criação de serviços jurídicos de apoio às vítimas, integrados a atendimento psicológico e social.

Com base nesses preceitos constitucionais, o Ministério da Justiça, por meio do Programa Nacional de Proteção a Testemunhas, estimula a implantação de serviços de apoio às vítimas de violência em diversos Estados, principalmente as vítimas de violência doméstica e de gênero. $\mathrm{O}$ Cravi, no entanto, é anterior a todas essas iniciativas, seu público é mais amplo e seu pioneirismo pode ser reconhecido em diversos aspectos do serviço.

Os coordenadores do Cravi fazem questão de ressaltar que sua intenção não é dar conta de todas as vítimas indiretas da violência na Grande São Paulo, até porque isso seria impossível diante da dimensão do problema e da escassez de recursos humanos e materiais do Centro. Tampouco existe a preocupação de reproduzir o modelo por meio da criação de vários “Cravi’s” na região 
metropolitana ou no interior do Estado, embora tal possibilidade não esteja totalmente descartada.

Como centro de referência, o principal objetivo do Cravi é difundir para outros órgãos governamentais e não-governamentais o conceito de "vítima indireta" da violência e chamar a atenção para a necessidade de um atendimento específico a esse público. Trata-se de fazer com que a metodologia de atendimento e as observações feitas pelo Cravi a partir de seu banco de dados possam ser úteis para postos de saúde, hospitais, delegacias, tribunais de justiça, serviços de assistência social e demais órgãos que atendem as vítimas indiretas de violência, além das organizações não-governamentais e centros de estudo que lidam com a questão. "O serviço pode ter uma função simbólica e normatizadora”, explica Valdir Assef Júnior, sociólogo do Instituto São Paulo Contra a Violência e um dos coordenadores do Centro.

Para reforçar sua atuação nesse sentido, o Cravi procura formar redes com outras instituições e serviços que lidam com as vítimas indiretas da violência. Outra preocupação, incorporada ao trabalho recentemente, é a busca de um atendimento integrado e interdisciplinar. Segundo os coordenadores do Centro, a abordagem interdisciplinar, que hoje inclui o Direito, o Serviço Social e a Psicologia, pode futuramente incorporar outras disciplinas, como Antropologia, História, Cinema, Jornalismo, etc. O trabalho interdisciplinar é um grande desafio para os técnicos do Cravi, pois implica a necessidade de conciliar diferentes formações profissionais e vínculos institucionais, já que alguns desses técnicos são contratados pelas ONGs parceiras do Centro e outros são funcionários públicos ligados a duas secretarias estaduais.

\section{Funcionamento}

O Cravi funciona em uma casa próxima ao centro de São Paulo e ao lado da Secretaria de Justiça e Defesa da Cidadania. Sua equipe é formada por 14 pessoas, sendo três coordenadores (o coordenador geral, ligado à Secretaria, e um de cada organização parceira), um advogado, duas assistentes sociais e seis psicólogos (todos contratados pelo Instituto Therapon Adolescência), além de uma psicanalista, também do Instituto, responsável pela supervisão do trabalho.

No início, o Cravi atendia apenas grupos familiares, até que começou a surgir também a demanda por um atendimento individual e por uma atenção especial às crianças e aos 
adolescentes. ${ }^{4}$ As sessões com crianças podem impedir que elas reproduzam a experiência violenta, como protagonistas ou como vítimas de mais violências.

No que se refere aos jovens, o Cravi planeja criar um espaço mais informal para atrair essa faixa de público, geralmente avessa a reuniões e ambientes onde há certa formalidade. Por enquanto, a equipe apenas participa esporadicamente de reuniões com grupos de jovens em determinadas comunidades e nos Centros de Integração da Cidadania (CICs) ${ }^{5}$. Também de forma esporádica o Cravi desenvolve atividades (oficinas sobre direitos humanos, cursos, etc.), em projetos executados por organizações não-governamentais que lidam com esse público, como o Centro de Direitos Humanos (CDH).

O caráter interdisciplinar do serviço e a busca por um trabalho mais integrado e eficiente fizeram com que o Centro, além do atendimento individual e familiar, passasse a oferecer também o atendimento em grupo. As intervenções em grupo proporcionam a criação de uma rede de apoio mútuo, na qual todos podem partilhar suas experiências de perda e dor com outras pessoas. Há três tipos de grupos: o aberto, o psicoterapêutico e o interdisciplinar.

O grupo aberto, coordenado por um psicólogo, tem esse nome porque a cada período determinado (geralmente um mês) permite a entrada de novos usuários. Já o grupo terapêutico possui um número fixo de oito integrantes, funcionando como uma espécie de terapia coletiva. O grupo interdisciplinar, coordenado por um profissional de cada área (Psicologia, Direito e Serviço Social), tem como característica o atendimento simultâneo de diversos usuários a partir de um tema definido.

De modo geral, os usuários tomam conhecimento do Centro por meio da divulgação "boca-aboca”, de reportagens na imprensa, ou de encaminhamentos feitos pela Polícia Civil, pela Casa Eliane de Grammont (ONG que atende mulheres vítimas de violência de gênero), pela Comissão de Direitos Humanos da Prefeitura de São Paulo e por outras instituições. Antes de ser encaminhado a um determinado profissional ou a um grupo, o usuário passa pelo processo de acolhimento, no qual ele pode falar de suas queixas, de suas demandas, de sua vivência com o fato trágico que o levou até ali.

\footnotetext{
${ }^{4}$ Foi justamente a necessidade de um trabalho específico com crianças e adolescentes que motivou a entrada do Instituto Therapon Adolescência como um dos parceiros do Centro. Mais tarde, porém, o Instituto passou a ter um papel mais amplo na parceria. Além disso, o atendimento às crianças, que era feito apenas por alguns técnicos, passou a ser tarefa de toda a equipe.

${ }^{5}$ Programa da Secretaria da Justiça e Defesa da Cidadania do Estado, que concentra, num mesmo espaço, diversos serviços públicos ligados à cidadania e oferece à população mecanismos de solução de pequenos conflitos.
} 
O Centro mantém um fluxo de 80 casos sendo atendidos e recebe uma média de aproximadamente 20 casos novos por mês. De acordo com os técnicos, os usuários chegam ao Centro bastante abalados, fragilizados e inseridos em um contexto de violência. Segundo Rachel Roitman, uma das responsáveis pelo atendimento psicológico do Cravi, a primeira queixa que eles costumam apresentar se refere à falta de um lugar que lhes possibilite falar abertamente sobre a tragédia. "Eles se sentem desamparados, sem uma rede em que possam compartilhar sua vivência”, afirma a psicóloga. As mortes relatadas pelos usuários nem sempre são recentes e às vezes são até previsíveis, dado o contexto de violência em que ocorrem. "Mesmo assim, são sempre acontecimentos que desestruturam as pessoas”, diz Rachel.

Por isso, o acolhimento inicial constitui um dos maiores desafios do Centro e uma de suas principais inovações. Na opinião dos coordenadores, essa primeira escuta coloca para os técnicos do Cravi a seguinte questão: qual a possibilidade de um serviço público ouvir vítimas de violência sem banalizar o assunto e sem transformá-lo em espetáculo? Há também a preocupação em evitar que o acolhimento se transforme em uma investigação sobre a vida do usuário. “Caminhamos sempre no fio da navalha entre distanciar-se demais e envolver-se demais com as histórias”, comenta Valdir Assef. Para enfrentar esse desafio, os técnicos do Cravi contam com as reuniões de supervisão institucional, nas quais as dificuldades do trabalho são discutidas por todos os técnicos com uma psicanalista do Instituto Therapon Adolescência.

Feito o acolhimento do usuário, a segunda fase é a do atendimento e encaminhamento. Nessa etapa, cresce a importância da rede de instituições com as quais o Cravi se relaciona, especialmente o Centro de Integração da Cidadania (CIC), o Juizado Especial Criminal da Família (Jecrimfam), o Centro de Saúde-Escola do Butantã, entre outros. Tais instituições recebem pessoas encaminhadas pelo Cravi, de acordo com a demanda apresentada: emissão de documentos, solução de conflitos familiares, alcoolismo, etc.

Ao mesmo tempo, o Cravi segue sua rotina de atendimentos individuais e em grupo, buscando reconstruir a vida dos usuários. "Muitas vezes, eles já sofreram várias violências e nem se deram conta”, diz a assistente social Karina Caritá. No decorrer das sessões, é possível notar uma evolução no comportamento dessas pessoas. O primeiro obstáculo a ser vencido é a descrença em relação às instituições públicas e a desconfiança em relação aos vizinhos e outros integrantes de seu meio social. 
Aos poucos, as vítimas indiretas da violência refazem suas histórias de vida e atribuem novos significados à própria experiência pessoal. A violência que sofreram passa a ser considerada sob uma perspectiva mais ampla, ligada ãs condições vigentes em toda a sociedade. "Quando chegam a esse ponto, elas começam a se colocar como sujeitos, agentes, cidadãos”, afirma Karina. Essa última fase do processo constitui o que os técnicos do Cravi chamam de “recuperação da potência”, que consiste em fortalecer a pessoa para que ela volte a enfrentar os desafios da vida.

O tempo para que esse estágio seja alcançado varia de um usuário para outro e o Cravi não estabelece um prazo para a conclusão do atendimento. Alguns se desligam do Centro espontaneamente, mesmo que suas demandas ainda não tenham sido atendidas, e outros sequer procuram os serviços para os quais são encaminhados.

Os que mantêm a freqüência recebem, além do apoio psicológico, uma ajuda para a reorganização individual e familiar, a fim de que consigam solucionar as dificuldades que surgem logo após a morte de um parente: requerimentos de pensão, encaminhamento de crianças e jovens para escolas e cursos profissionalizantes, encaminhamento para médicos e psiquiatras, etc.

Para as pessoas que estão sob ameaça, o Cravi providencia o encaminhamento a um abrigo sigiloso do Departamento de Homicídios e Proteção à Pessoa (DHPP), da Polícia Civil de São Paulo. As assistentes sociais do Cravi observam, no entanto, que essa decisão é precedida de uma análise cuidadosa, pois a transferência para o abrigo implica o rompimento de vínculos sociais, além de todos os inconvenientes de uma vida secreta.

Na área jurídica, o Cravi ajuda os usuários no acompanhamento dos inquéritos policiais e dos processos na justiça. É importante ressaltar, contudo, que o setor jurídico do Cravi não atua na defesa das vítimas - trabalho da Defensoria Pública ou de advogados particulares.

\section{Ouvindo os usuários do Centro}

Foi o atendimento jurídico que levou a ex-empregada doméstica Clotilde Maria de Jesus, de 61 anos, a procurar o Cravi, em 2002. No entanto, ela nunca conseguiu saber por quem e por que seu filho de 17 anos foi assassinado. O inquérito foi arquivado pela polícia. “Eu ficava ansiosa 
para saber se alguém tinha sido preso, mas parei de ficar ligando para o DEIC ${ }^{6,}$, conta. De fato, uma parte do trabalho dos técnicos é impedir que a pessoa fique presa ao passado, imobilizada pelo trauma. "Procuramos evitar que a pessoa acompanhe o processo como se fosse a continuidade da vida do filho”, afirma o advogado do Cravi, Shigueo Kuwahara.

Mesmo com o arquivamento do inquérito, Clotilde continuou a buscar a ajuda do Centro porque, segundo ela, "o trabalho [do Cravi] tira a pessoa do fundo do poço, do sofrimento”. No Centro, ela recebe uma cesta básica, ajuda psicológica e reúne forças para tocar a vida adiante, cuidando do neto e de seus outros dois filhos.

A publicitária Paula do Vale Nascimento, 41 anos, também elogia o serviço prestado pelo Cravi. “Não há dinheiro que pague”, diz. Ela procurou o Centro cerca de dois anos depois de um assalto em sua casa. O padrasto de Paula morreu baleado pelos assaltantes e ela mesma sofreu ferimentos na boca que ainda hoje requerem tratamento. Depois disso, não conseguia mais se concentrar no trabalho, enfrentava dificuldades para dormir e se alimentar e chegou a pensar em suicídio. O acontecimento deixou seqüelas em toda a sua família: a mãe, o irmão e os filhos de Paula.

Quando chegou ao Cravi, ela não gostou do atendimento inicial e teve uma reação típica das vítimas indiretas da violência: “Pensei: 'tudo que é do Estado é ruim'. Até que a assistente social iniciou uma nova terapia e eu comecei a melhorar”, lembra. “Estou reaprendendo a viver; antes eu nem conseguia contar o que me aconteceu”. O filho mais novo de Paula, de 12 anos, também freqüenta o Cravi. “Ele dizia que queria ser matador; agora fala em ser aviador”.

\section{Dificuldades}

Em meio aos elogios ao trabalho do Cravi, tanto Paula como Clotilde queixam-se das periódicas paralisações do atendimento, motivadas pelas interrupções dos convênios. Essa, aliás, é uma queixa comum a todos os técnicos do Centro, inclusive os coordenadores. Cada renovação de convênio requer trâmites burocráticos que demandam vários meses. De acordo com os técnicos, tem havido algum avanço nesse aspecto, pois as interrupções são cada vez mais curtas, mas o Centro ainda chega a interromper o atendimento ao público por até dois meses, à espera da

\footnotetext{
${ }^{6}$ Departamento Estadual de Investigações Criminais, da Polícia Civil de São Paulo.
} 
formalização de novos convênios. “Nossa primeira preocupação ainda é manter o Cravi funcionando 12 meses por ano”, diz o coordenador geral Fabrício Toledo de Souza.

Essas interrupções demonstram a fragilidade institucional do Cravi, que não conta com um orçamento fixo nem dispõe de um quadro permanente de técnicos, já que as parcerias com as ONG não são estáveis. Atualmente, a instituição conta com um repasse anual de R \$ 180 mil do Ministério da Justiça e de R\$ 60 mil da Secretaria de Justiça e Defesa da Cidadania do Estado de São Paulo, responsável também pela infra-estrutura física (prédio, instalações, equipamentos, etc.).

Além de ameaçar a continuidade do trabalho numa eventual mudança de governo, a interrupção dos convênios e a demora em renová-los prejudicam a consolidação da rede de instituições com as quais o Centro deve dialogar. Para facilitar esse diálogo, seria importante também que houvesse maior divulgação do serviço.

\section{Inovações}

Apesar desses obstáculos, a equipe realiza atividades que vão além do atendimento ao público. O Cravi conseguiu, por exemplo, traçar o perfil socioeconômico de seus usuários e mapear o perfil da vítima indireta de violência na Grande São Paulo, o que pode subsidiar a implementação de políticas públicas. No entanto, falta uma avaliação sobre a resposta dos usuários ao atendimento, seja no que se refere à sua opinião sobre o serviço, seja no que diz respeito à solução das demandas apresentadas. Não existe um levantamento sobre o que aconteceu com os usuários do Cravi depois que se desligaram do Centro.

Na ausência de uma avaliação sistematizada a respeito do impacto de seus serviços, o Cravi baseia-se na observação da equipe sobre como os usuários estão reagindo ao atendimento. Os técnicos observam o fluxo de cada usuário pelo Centro, sendo considerado um sinal positivo a passagem pelas três áreas - social, psicológica e jurídica. Além disso, procuram verificar se as pessoas estão buscando e tendo acesso aos serviços públicos e se estão superando o trauma.

O trabalho se desdobra em pesquisas e o Centro mantém uma interlocução constante com o Núcleo de Estudos da Violência da Universidade de São Paulo (NEV-USP), a Comissão de Direitos Humanos do Município de São Paulo, o Centro de Integração da Cidadania, o Fórum de Justiça da Barra Funda e o Centro de Saúde-Escola do Butantã, entre outras instituições. O Cravi também chegou a oferecer um curso sobre direitos humanos aos usuários da Casa Eliane de 
Grammont e participou do Fórum em Defesa da Vida do Jardim Ângela ${ }^{7}$. Os coordenadores destacam que o Centro tem sido solicitado a emitir seu parecer sobre projetos de lei nas áreas de segurança pública e de direitos humanos.

Tais atividades demonstram a relevância dessa instituição, cujo papel possivelmente seria ampliado se houvesse maior divulgação de seus serviços, além de uma dotação orçamentária e um regime de funcionamento mais estáveis. Afinal, depois de atender mais de 5.500 pessoas ao longo dos últimos sete anos, o Cravi apresenta diversos aspectos que ainda podem ser considerados inovadores. A abordagem interdisciplinar e integrada e a gestão compartilhada com organizações não-governamentais são alguns desses aspectos. Mas talvez o próprio enfoque na problemática das vítimas indiretas de violência seja a principal inovação. No momento em que toda a sociedade parece atônita diante do número de mortes causadas pela violência, o Cravi é uma das poucas vozes a chamar a atenção para a dor dos sobreviventes.

\footnotetext{
${ }^{7}$ A partir de um trabalho iniciado por um padre local, apoiado posteriormente pelo Projeto Criança Esperança (da TV Globo e do Unicef), o Fórum desenvolve uma série de atividades neste que já foi o bairro mais violento do município de São Paulo. Na atividade que o Cravi ajudou a desenvolver, um grupo de mães mapeou os recursos do bairro e pesquisou a história local. A experiência culminou com um curso sobre direitos humanos.
} 


\section{Bibliografia}

AFFONSO, R.M.L.; MOTA, E.M.T.; PEREIRA, A.C. A construção de um modelo clínico de atendimento psicológico a famílias vítimas de violência da cidade de São Paulo. Psikhê - Revista do Curso de Psicologia do Centro Universitário Faculdades Metropolitanas Unidas. São Paulo, 5(2): 26-40, jul./dez., 2000

AGUIAR, Thaís. Pesquisa aponta falta de políticas públicas para vítimas indiretas da violência. Revista eletrônica Desarme.org (www.desarme.org). 11 de março de 2005.

AGUIAR, Thaís. Da dor à ação: o impacto para as famílias das mortes causadas pela violência armada. Revista eletrônica Desarme.org (www.desarme.org). 11 de março de 2005.

MATTOS, Janaína Valéria de e LOTTA, Gabriela. Dar apoio às vítimas de violência. Dicas Idéias para a ação municipal, $n^{0}$ 202. São Paulo: Instituto Polis.

MORAES, Alexandre de. Direitos Humanos das Vítimas. Folha de S. Paulo, 15 de fevereiro de 2002.

Artigo recebido em: 12/06/2006 e aceito em 10/09/2006. 